\title{
The relationship of psychosocial factors to mammograms, physical activity, and fruit and vegetable consumption among sisters of breast cancer patients
}

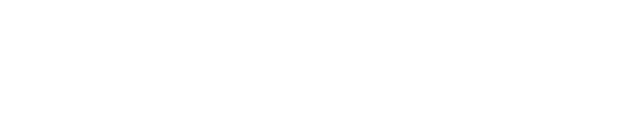

\author{
Sheri J Hartman' \\ Shira I Dunsiger' \\ Paul B Jacobsen ${ }^{2}$ \\ 'Centers for Behavioral and \\ Preventive Medicine, The Miriam \\ Hospital and W Alpert Medical School \\ of Brown University, Providence, RI; \\ ${ }^{2}$ Department of Health Outcomes \\ and Behavior, $\mathrm{H}$ Lee Moffitt Cancer \\ Center and Research Institute, \\ Tampa, FL, USA
}

\begin{abstract}
This study examined the relationship of psychosocial factors to health-promoting behaviors in sisters of breast cancer patients. One hundred and twenty sisters of breast cancer patients completed questionnaires assessing response efficacy of mammography screenings, physical activity, and fruit and vegetable consumption on decreasing breast cancer risk, breast cancer worry, involvement in their sister's cancer care, mammography screenings, physical activity, and fruit and vegetable consumption. Results indicate that greater perceived effectiveness for mammograms was associated with a $67 \%$ increase in odds of yearly mammograms. Greater involvement in the patient's care was associated with a 7\% decrease in odds of yearly mammograms. Greater perceived effectiveness for physical activity was significantly related to greater physical activity. There was a trend for greater perceived effectiveness for fruits and vegetables to be associated with consuming more fruits and vegetables. Breast cancer worry was not significantly associated with the outcomes. While perceived effectiveness for a specific health behavior in reducing breast cancer risk was consistently related to engaging in that health behavior, women reported significantly lower perceived effectiveness for physical activity and fruits and vegetables than for mammograms. Making women aware of the health benefits of these behaviors may be important in promoting changes.
\end{abstract}

Keywords: breast cancer risk, mammograms, physical activity, diet, perceived effectiveness

\section{Introduction}

Women with a family history of breast cancer have a two to four times increased risk for developing breast cancer. ${ }^{1}$ Consequently, sisters of breast cancer patients may feel particularly vulnerable to developing the disease. It is currently not known how the experience of having a sister with breast cancer may impact obtaining mammograms and health-promoting behaviors that could reduce breast cancer risk. The purpose of this study is to identify whether psychosocial factors are related to mammograms and health-promoting behaviors in sisters of breast cancer patients.

Mammograms have been shown to be effective for reducing breast cancer mortality; ${ }^{1}$ therefore, it is particularly important for sisters of breast cancer patients to obtain yearly mammograms. While some risk factors cannot be changed, others such as physical activity and maintaining a healthy weight through a proper diet are modifiable. Research has consistently found an inverse relationship between regular physical activity and breast cancer risk..$^{2-5}$ Literature reviews have found that physical activity is associated with, on average, a $20 \%$ risk reduction in breast cancer ${ }^{4,6}$
Correspondence: Sheri J Hartman Centers for Behavioral and Preventive Medicine, Suite IB, I67 Point St, Providence, RI 02903

$\mathrm{Tel}+\mathrm{I} 4017938274$

Fax + I 40I 7938078

Email shartman@lifespan.org 
and support that there is a dose-response relationship for physical activity and breast cancer risk. ${ }^{6,7}$ In addition to the direct benefits of physical activity on breast cancer, physical activity can also reduce adiposity, ${ }^{8-10}$ which is associated with increased risk of lifetime breast cancer in postmenopausal women. ${ }^{11-15}$ Another way to influence weight is to eat a diet high in low calorie dense foods, such as fruits and vegetables. While research examining the direct relationship between a diet high in fruits and vegetables and breast cancer risk has been mixed, ${ }^{15-20}$ some studies have found a protective effect for fruits and vegetables. ${ }^{16,17,19}$ Therefore, a diet high in fruits and vegetables may help to reduce breast cancer risk itself as well as help with weight loss and weight maintenance to reduce breast cancer risk. For sisters of breast cancer patients, being physically active and eating a diet high in fruits and vegetables could be important in decreasing their risk of breast cancer. In order to encourage health-promoting behaviors in sisters of breast cancer patients it is important to know what factors relate to engagement in such behaviors.

The goal of the current study is to examine how perceived effectiveness of a health behavior, breast cancer worry, and involvement in the breast cancer care relate to obtaining mammograms and health-promoting behaviors in sisters of breast cancer patients. We hypothesized that women who reported greater perceived effectiveness for mammograms, greater breast cancer worry, and greater involvement in their sister's breast cancer care would be more likely to have yearly mammograms. Second, women who reported greater perceived effectiveness for physical activity, greater breast cancer worry, and greater involvement in their sister's breast cancer care would report higher levels of physical activity. Finally, women who reported greater perceived effectiveness for fruit and vegetable consumption, greater breast cancer worry, and greater involvement in their sister's breast cancer care would report greater consumption of fruit and vegetables.

\section{Methods}

\section{Participants}

We first recruited women with breast cancer to obtain their sisters' contact information and permission to contact their sisters. The breast cancer patients were recruited from the Moffitt Cancer Center. Patient eligibility criteria were: (a) at least 2 months post treatment; (b) no history of additional cancer other than basal cell; (c) diagnosed with Stage 0, I, or II breast cancer; (d) surgically treated with lumpectomy or mastectomy; (e) received chemotherapy, radiation, or both; (f) able to provide informed consent; (g) able to speak and read English. Patients who consented were asked to provide contact information for multiple sisters, and all sisters were contacted for the study.

Sister eligibility criteria were: (a) 45 to 70 years old; (b) able to provide informed consent; (c) able to speak and read English; (d) no history of breast cancer; (e) no breast biopsies within the past 5 years; (f) only one first-degree relative diagnosed with breast cancer; ( $g$ ) have not been tested for the BRCA1/2 genes. Age eligibility was based on the US Preventive Services Task Force recommendation that women between 40 and 70 years old obtain mammography screenings every 2 years. ${ }^{21}$ Because women's mammography screenings for the past 5 years were assessed, eligibility was limited to women between the ages of 45 and 70 . Sisters who were interested and eligible were given the option to complete the survey through the mail or online. This research was approved by the Institutional Review Board at the University of South Florida.

\section{Measures}

The sister's demographic information was obtained through self-report, including date of birth, race, marital status, income, education, and objective risk of breast cancer. Objective risk was assessed using the Gail model which provides a 5-year and a lifetime percentage risk of developing breast cancer. ${ }^{22}$ The breast cancer patient's clinical information was obtained through medical records. Variables included date of birth, date of diagnosis, stage of breast cancer, and type of treatments.

Perceived effectiveness of mammograms was assessed with four questions modeled from previous research. ${ }^{23-25}$ Perceived effectiveness for physical activity and for fruit and vegetable consumption were each assessed with a single item. Items were on 6-point Likert scale ( 1 = strongly disagree; 6 = strongly agree).

The Cancer Worry Scale assessed the extent that breast cancer-specific worry interfered with daily functioning on a 4-point Likert scale ( $1=$ not at all or rarely; $4=\mathrm{a}$ lot $){ }^{26}$

Participant's involvement in her sister's cancer care was assessed using six items. The first item "To what extent were you personally involved in your sister's cancer treatment and care?" was modeled from previous research. ${ }^{27}$ The other five items assessed the frequency of communication, attending appointments, and providing assistance on a 5-point Likert scale ( $1=$ rarely to $5=$ frequently). Items were summed to create a total score with higher scores indicating greater involvement in care.

Women were asked the number of mammograms they obtained in the past 5 years. Participants were classified as 
having had annual mammograms if they reported five or more mammograms.

Physical activity was assessed with the Godin LeisureTime Exercise Questionnaire (LSI). ${ }^{28}$ The LSI consists of three questions that assess the average frequency of mild, moderate, and strenuous exercise in a typical week. A total score is created by multiplying the frequency of mild, moderate, and strenuous exercise by 3,5 , and 9, respectively, and summing. ${ }^{28}$

Fruit and vegetable consumption was measured with the By Meal Screener (BMS), a brief fruit and vegetable screener used in the National Institutes of Health's Eating at America's Table study. ${ }^{29}$ Participants are asked to indicate the frequency and quantity of fruits and vegetables they consumed in the morning, afternoon, and evening in the past month. Additional questions assess frequency and quantity of eight more specific categories of fruits and vegetables consumed at any time of the day in the past month. A total score is calculated by converting quantity to a standard scale for each type of fruit and vegetable, multiplying by the frequency, and summing.

\section{Statistical analyses}

Descriptive statistics (means and standard deviation for continuous variables and $\mathrm{n}$ sizes and percents for categorical variables) were used to characterize the demographic characteristics of the breast cancer patients and their sisters.

Logistic regression was used to test the association between response efficacy for mammography screening, breast cancer worry, involvement in sister's care and the odds of obtaining yearly mammography screening, while controlling for blood relationship and an indicator of whether multiple sisters were participating in the study. Preliminary analysis of the correlation between the covariates of interest was carried out in order to test for multicollinearity of the predictors. All potential predictors of yearly mammography screening were mean centered. Residual and influence diagnostics were assessed after a final model was established in order to address model assumptions.

Linear regression models were used to test for the association between response efficacy for physical activity, breast cancer worry, and involvement in sister's care on the mean of the continuous responses (ie, reported physical activity and reported fruit and vegetable intake), while controlling for income and an indicator of whether multiple sisters were participating in the study. Again, potential predictors were mean centered in order to estimate a meaningful intercept term. Finally, residual and influence diagnostics were assessed to determine whether model assumptions were met.

\section{Results \\ Participants}

Letters were mailed to 723 breast cancer patients about the current study. Of the 497 patients who were able to be contacted by phone and interested in additional information, 150 had an eligible sister. Consent forms were returned by 132 women and provided a total of 193 sisters' contact information. Of the 193 sisters, 141 were eligible and 120 completed the study. See Figure 1 for a complete breakdown of recruitment and reasons for ineligibility. In summary, 132 of 150 of eligible patients (88\%) and 120 of 141 eligible sisters (85\%) completed their respective study requirements.

\section{Patients' demographic and clinical information}

The 90 breast cancer patients whose sisters participated in the study ranged in age from 43-71 years (mean = 57.7; standard deviation $=7.2$ ). They had been diagnosed with breast cancer between 1.5 and 6.6 years ago ( mean $=3.7$; standard deviation $=1.5$ ). Breast cancer was diagnosed at stage 0 for eight patients, stage I for 41 patients, and stage II for 40 patients. Thirty-one received radiotherapy only, 23 had received chemotherapy only, and 35 had received chemotherapy with radiotherapy.

\section{Sisters' demographic and clinical information}

A total of 120 sisters of breast cancer patients, from 90 different families, completed the study. Sixty-seven sisters were the only sisters from their family participating and 53 had at least one sibling in the study. Participants ranged from 45-69 years $($ mean $=56.2 ;$ standard deviation $=6.0)$, majority had partial college education or greater $(82 \%)$, were non-Hispanic (94\%), White (95\%), married (72\%), and had a household income of $\$ 40,000$ or greater $(79 \%)$. Five-year breast cancer risk estimate averaged $2.5 \%$ (range $=1.0 \%-5.1 \%$ ) and lifetime breast cancer risk estimate averaged 15.3\% (range $=7.8 \%-27.6 \%$ ).

Participants' average ratings for perceived effectiveness were 5.21 (standard deviation $=0.80)$ for mammograms, 4.32 (standard deviation $=1.47$ ) for physical activity, 4.36 (standard deviation $=1.45$ ) for fruit and vegetable consumption. Compared to mammograms, participants had significantly lower perceived effectiveness for physical activity $(\mathrm{t}=6.28$, 


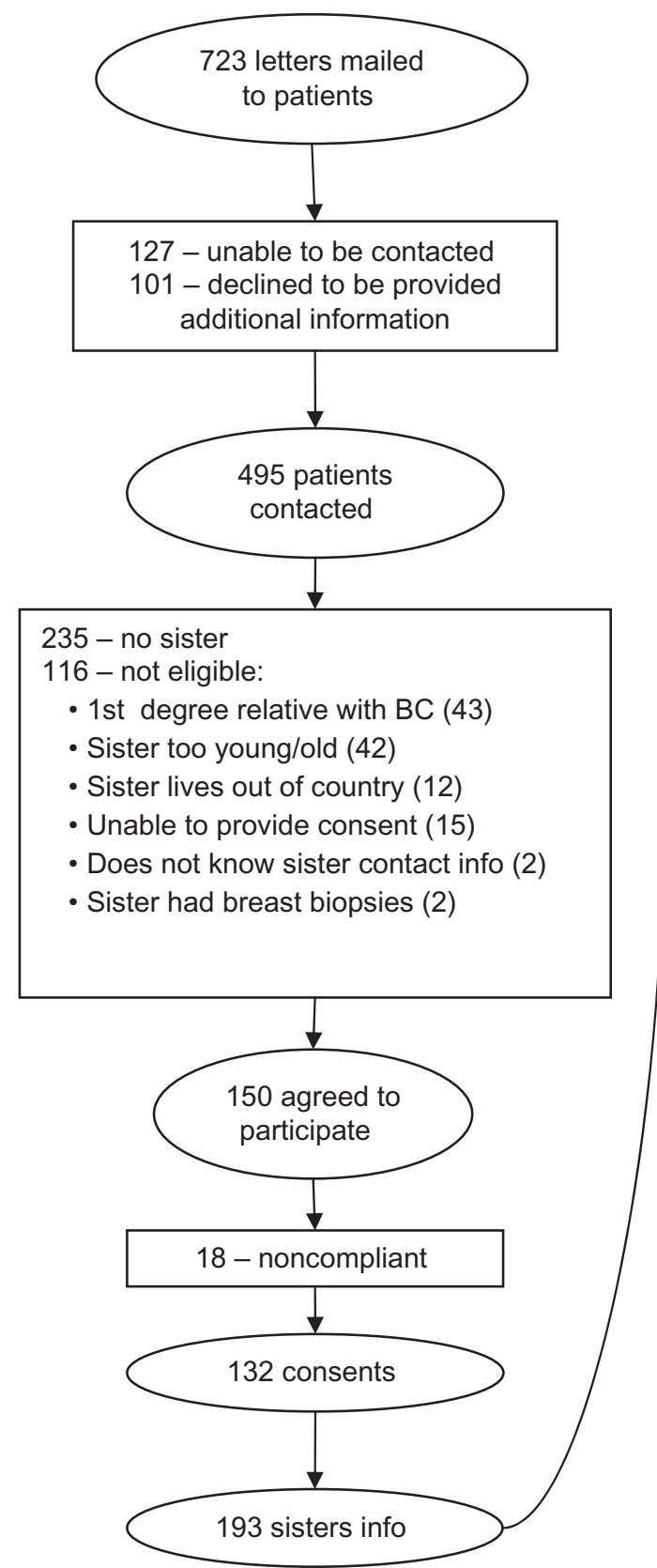

Figure I Patient and sister accrual.

$P<0.01)$ and fruit and vegetable consumption $(\mathrm{t}=6.05$, $P<0.01)$. The average ratings on the breast cancer worry scale was 1.63 (standard deviation $=0.45$ ). The average rating on the involvement in sister breast cancer care measure was 2.79 (standard deviation $=1.22)$.

\section{Annual mammograms}

The reported number of mammograms in the past 5 years ranged from 0 to 10 . Eighty-one women were classified as having annual mammograms and 39 were classified as having less than annual mammograms.

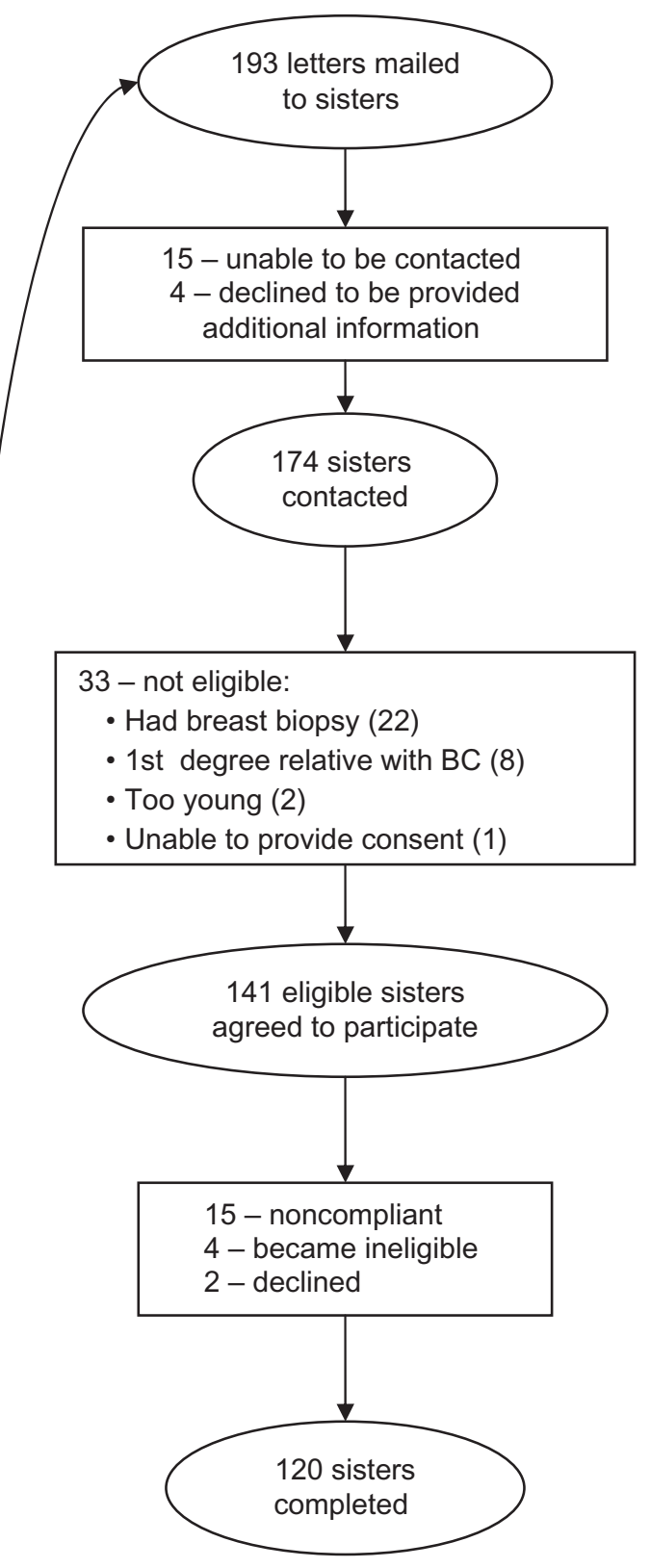

There was a trend for effectiveness for mammograms and the odds of having had annual mammograms $(b=0.51$, standard error $=0.27, \chi^{2}=3.59, P=0.06$ ). A one-unit increase in perceived effectiveness was associated with a $67 \%$ increase in odds of having yearly mammograms, while controlling for the other psychosocial variables and relevant demographics. There was a significant relationship between involvement in the patient's breast cancer and the odds of having had annual mammograms $(\mathrm{b}=-0.07$, standard error $=0.03$, $\left.\chi^{2}=4.28, P=0.04\right)$. Greater involvement in the patient's breast cancer care was associated with a $7 \%$ decrease in 
Table I Logistic regression for annual mammography screenings

\begin{tabular}{|c|c|c|c|c|c|}
\hline Parameter & DF & Estimate & SE & Chi-Square & $\operatorname{Pr}>$ ChiSq \\
\hline Intercept & I & 0.41 & 1.15 & 0.13 & 0.72 \\
\hline Breast cancer worry & I & -0.09 & 0.12 & 0.52 & 0.47 \\
\hline Involvement in care & I & -0.07 & 0.03 & 4.28 & 0.04 \\
\hline PE - mammography & I & 0.51 & 0.27 & 3.59 & 0.06 \\
\hline Other family in study & I & -0.20 & 0.51 & 0.16 & 0.69 \\
\hline Blood relation & I & -0.65 & 0.72 & 0.82 & 0.37 \\
\hline \multirow[t]{3}{*}{ Income } & I & 0.25 & 0.17 & 2.07 & 0.15 \\
\hline & & \multicolumn{4}{|c|}{ Odds ratio } \\
\hline & & \multicolumn{2}{|c|}{ Effect estimate } & \multicolumn{2}{|c|}{$\mathbf{9 5} \%$ confidence interval } \\
\hline Breast cancer worry & & \multicolumn{2}{|c|}{0.92} & \multicolumn{2}{|c|}{$0.72-1.17$} \\
\hline Involvement in care & & \multicolumn{2}{|l|}{0.93} & \multicolumn{2}{|l|}{$0.87-1.00$} \\
\hline $\mathrm{RE}$ - mammography & & \multicolumn{2}{|l|}{1.67} & \multicolumn{2}{|l|}{$0.98-2.84$} \\
\hline Other family in study & & \multicolumn{2}{|l|}{0.82} & \multicolumn{2}{|l|}{$0.30-2.23$} \\
\hline Blood relation & & \multicolumn{2}{|l|}{0.52} & \multicolumn{2}{|l|}{$0.13-2.14$} \\
\hline Income & & 1.29 & & \multicolumn{2}{|l|}{$0.9 \mid-1.81$} \\
\hline
\end{tabular}

Abbreviations: DF, degrees of freedom; PE, perceived effectiveness; SE, standard error

odds of having yearly mammograms, while controlling for the other psychosocial variables and relevant demographics.

Breast cancer worry was not significantly related to annual mammograms (Table 1).

\section{Physical activity}

There was a significant relationship between perceived effectiveness for physical activity and scores on the LSI $(b=2.44$, standard error $=1.09, \mathrm{t}=2.24, P=0.03$ ), while controlling for the other psychosocial variables and relevant demographics, such that greater perceived effectiveness for physical activity was associated with greater engagement in physical activity. Involvement in the patient's care and breast cancer worry were not significantly associated with physical activity. Income was significantly associated with physical activity $(b=3.27$, standard error $=1.33, \mathrm{t}=2.47, P=0.02$ ), such that higher income was associated with greater average physical activity (Table 2).

\section{Fruits and vegetables}

There was a trend for the association between perceived effectiveness for fruit and vegetable consumption and scores on

Table 2 Linear regression for physical activity

\begin{tabular}{llcccc}
\hline Parameter & DF & Estimate & SE & t value & Pr $>|\mathbf{t}|$ \\
\hline Intercept & $\mathrm{I}$ & 7.24 & 6.23 & $\mathrm{I} .16$ & 0.25 \\
Breast cancer worry & $\mathrm{I}$ & 0.28 & 0.95 & 0.29 & 0.77 \\
Involvement in care & $\mathrm{I}$ & -0.06 & 0.26 & -0.25 & $0.8 \mathrm{I}$ \\
PE - physical activity & $\mathrm{I}$ & 2.44 & $\mathrm{I} .09$ & 2.24 & 0.03 \\
Other family in study & $\mathrm{I}$ & $3.3 \mathrm{I}$ & 3.86 & 0.86 & 0.39 \\
Income & $\mathrm{I}$ & 3.27 & $\mathrm{I} .33$ & 2.47 & 0.02 \\
\hline
\end{tabular}

Abbreviations: DF, degrees of freedom; PE, perceived effectiveness; SE, standard error. the BMS $(b=0.23$, standard error $=0.13, \mathrm{t}=1.80, P=0.07)$, while controlling for the other psychosocial variables and relevant demographics, such that perceived effectiveness for fruits and vegetables was associated with greater fruit and vegetable consumption. Involvement in the patient's care and breast cancer worry were not significantly associated with fruit and vegetable consumption (Table 3).

\section{Discussion}

The aim of the study was to examine how psychosocial factors relate to health-promoting behaviors in sisters of breast cancer patients. Results indicated that greater perceived effectiveness for a health behavior was related to engaging in that health behavior. These findings are consistent with previous research, ${ }^{30,31}$ and build upon this research by extending the relationship to sisters of breast cancer patients. Results also indicated that breast cancer worry was not associated with the health behaviors. While this was contrary to our hypothesis, it is consistent with previous research that has found

Table 3 Linear regression for fruit and vegetable consumption

\begin{tabular}{llcccc}
\hline Parameter & DF & Estimate & SE & t value & Pr $>|\mathbf{t}|$ \\
\hline Intercept & $\mathrm{I}$ & 4.23 & 0.73 & $5.8 \mathrm{I}$ & $<0.0 \mathrm{I}$ \\
Breast cancer worry & $\mathrm{I}$ & -0.15 & $0.1 \mathrm{I}$ & -1.38 & 0.17 \\
Involvement in care & $\mathrm{I}$ & 0.03 & 0.03 & 0.87 & 0.39 \\
PE - fruits and & $\mathrm{I}$ & 0.23 & 0.13 & 1.80 & 0.07 \\
$\begin{array}{l}\text { vegetables } \\
\text { Other family }\end{array}$ & $\mathrm{I}$ & -0.08 & 0.45 & -0.18 & 0.86 \\
$\begin{array}{l}\text { in study } \\
\text { Income }\end{array}$ & $\mathrm{I}$ & -0.23 & 0.15 & -1.46 & 0.15 \\
\hline
\end{tabular}

Abbreviations: DF, degrees of freedom; PE, perceived effectiveness; SE, standard error. 
mixed results for the relationship between worry and health behaviors. ${ }^{32,33}$ One explanation for the lack of relationship in this study may be due to the low endorsement of breast cancer worry. Although it was hypothesized that greater involvement in sister's care would be associated with greater likelihood of annual mammograms, the opposite relationship was found. While this was inconsistent with our hypothesis, previous research has not assessed how involvement in a relative's breast cancer care relates to screening and health-promoting behaviors; therefore, this unanticipated finding provides important new information. This finding may be because the 5-year period assessed for mammograms overlapped with the breast cancer patient's diagnosis and treatment. Perhaps participants who spent more time taking care of their sister's had less time for their own care, including obtaining regular mammograms. Involvement in breast cancer care was not significantly associated with physical activity or fruit and vegetable consumption.

Several limitations should be noted. First, the sample was predominantly Caucasian and fairly homogenous, limiting the generalizability of the results. Second, the data was based on self-report, so the accuracy of the information about mammography screening and health behaviors is unknown. Third, the cross-sectional design did not allow for assessing how the psychosocial factors relate to changes in the healthpromoting behaviors. Finally, the lack of a comparison group without a family history of breast cancer limits the ability to determine differences between women with and without a family history of breast cancer.

The present study found that women were generally compliant with obtaining annual mammograms, suggesting that sisters of breast cancer patients may not require intervention to promote mammograms. On the other hand, greater involvement in the sister's cancer care may be related to decreased odds of having annual mammogram. Since sisters of breast cancer patients are at increased risk for breast cancer it may be important to intervene with these women to ensure that additional time taking care of their sister does not ultimately decrease their care for themselves. The current study also found a consistent relationship between perceived effectiveness for a specific health behavior and engaging in that health behavior. However, the sisters in the present study reported significantly lower perceived effectiveness for physical activity and fruit and vegetable consumption than they reported for mammograms. Therefore, making women aware of the health benefits of different behaviors may be one important method to increase the behavior. The current study also found that lower income was related to less physical activity which suggests that interventions targeting women with lower socioeconomic status may be warranted.

Future studies are needed that compare women with and without a family history of breast cancer to examine what impact family history has on women's health-promoting behaviors. Future research should include more diverse samples. Research should examine ways to intervene with women who may be at increased risk for not engaging in these health-promoting behaviors such as women with greater care giving responsibilities, lower income, and lower perceived effectiveness of the health behavior.

\section{Disclosure}

The authors report no conflicts of interest in this work.

\section{References}

1. American Cancer Society. Breast cancer facts and figures 2007-2008. 2007. Available from: http://www.cancer.org/downloads/STT/BCFFFinal.pdf. Accessed October 12, 2008.

2. International Agency for Research on Cancer. IARC handbooks of cancer prevention: weight control and physical activity. Vol 6. Lyon, France: IARC Press; 2002.

3. Lee IM, Oguma, Y. Physical activity. In: Schottenfeld D, Fraumeni JF Jr, editors. Cancer epidemiology and prevention. 3rd ed. New York: Oxford University Press; 2006.

4. McTiernan A. Mechanisms linking physical activity with cancer. Nat Rev Cancer. 2008;8(3):205-211.

5. Phipps AI, Chlebowski RT, Prentice R, et al. Body size, physical activity, and risk of triple-negative and estrogen receptor-positive breast cancer. Cancer epidemiol biomarkers prev. 2011;20(3):454-463.

6. Monninkhof EM, Elias SG, Vlems FA, et al. Physical activity and breast cancer: a systematic review. Epidemiology. 2007;18(1):137-157.

7. Friedenreich CM, Cust AE. Physical activity and breast cancer risk: impact of timing, type and dose of activity and population subgroup effects. Br J Sports Med. 2008;42(8):636-647.

8. Donnelly JE, Blair SN, Jakicic JM, Manore MM, Rankin JW, Smith BK. Appropriate physical activity intervention strategies for weight loss and prevention of weight regain for adults. Med Sci Sports Exerc. 2009;41(2):459-471.

9. Saris WH, Blair SN, van Baak MA, et al. How much physical activity is enough to prevent unhealthy weight gain? outcome of the IASO 1st Stock Conference and consensus statement. Obes Rev. 2003;4(2): 101-114.

10. Wing RR. Physical activity in the treatment of the adulthood overweight and obesity: current evidence and research issues. Med Sci Sports Exerc. 1999;31(Suppl 11):S547-S552.

11. Carmichael AR, Bates T. Obesity and breast cancer: a review of the literature. Breast. 2004;13(2):85-92.

12. Patterson RE, Cadmus LA, Emond JA, Pierce JP. Physical activity, diet, adiposity and female breast cancer prognosis: a review of the epidemiologic literature. Maturitas. 2010;66(1):5-15.

13. Renehan AG, Tyson M, Egger M, Heller RF, Zwahlen M. Body-mass index and incidence of cancer: a systematic review and meta-analysis of prospective observational studies. Lancet. 2008;371(9612):569-578.

14. Carmichael AR. Obesity as a risk factor for development and poor prognosis of breast cancer. BJOG. 2006;113(10):1160-1166.

15. Michels KB, Mohllajee AP, Roset-Bahmanyar E, Beehler GP, Moysich KB. Diet and breast cancer: a review of the prospective observational studies. Cancer. 2007;109(Suppl 12):2712-2749. 
16. Gandini S, Merzenich H, Robertson C, Boyle P. Meta-analysis of studies on breast cancer risk and diet: the role of fruit and vegetable consumption and the intake of associated micronutrients. Eur J Cancer. 2000;36(5):636-646.

17. Engeset D, Dyachenko A, Ciampi A, Lund E. Dietary patterns and risk of cancer of various sites in the Norwegian European Prospective Investigation into Cancer and Nutrition cohort: the Norwegian Women and Cancer study. Eur J Cancer Prev. 2009;18(1):69-75.

18. Riboli E, Norat T. Epidemiologic evidence of the protective effect of fruit and vegetables on cancer risk. Am J Clin Nutr. 2003;78(Suppl 3): 559S-569S.

19. Lissowska J, Gaudet MM, Brinton LA, et al. Intake of fruits, and vegetables in relation to breast cancer risk by hormone receptor status. Breast Cancer Res Treat. 2008;107(1):113-117.

20. Key TJ. Fruit and vegetables and cancer risk. Br J Cancer. 2011;104(1): 6-11.

21. US Preventive Services Task Force. Screening for breast cancer: recommendations and rationale. Ann Intern Med. 2002;137(5 Part 1): 344-346.

22. Gail MH, Brinton LA, Byar DP, et al. Projecting individualized probabilities of developing breast cancer for white females who are being examined annually. J Natl Cancer Inst. 1989;81(24):1879-1886.

23. Azzarello LM, Dessureault S, Jacobsen PB. Sun-protective behavior among individuals with a family history of melanoma. Cancer Epidemiol Biomarkers Prev. 2006;15(1):142-145.

24. Jackson KM, Aiken LS. A psychosocial model of sun protection and sunbathing in young women: the impact of health beliefs, attitudes, norms, and self-efficacy for sun protection. Health Psychol. 2000; 19(5):469-478.
25. Vadaparampil ST, Jacobsen PB, Kash K, Watson IS, Saloup R, Pow-Sang J. Factors predicting prostate specific antigen testing among first-degree relatives of prostate cancer patients. Cancer Epidemiol Biomarkers Prev. 2004;13(5):753-758.

26. Lerman C, Trock B, Rimer BK, Jepson C, Brody D, Boyce A. Psychological side effects of breast cancer screening. Health Psychol. 1991; 10(4):259-267.

27. Van Dooren S, Seynaeve C, Rijnsburger AJ, et al. The impact of having relatives affected with breast cancer on psychological distress in women at increased risk for hereditary breast cancer. Breast Cancer Res Treat. 2005;89(1):75-80.

28. Godin G, Jobin J, Bouillon J. Assessment of leisure time exercise behavior by self-report: a concurrent validity study. Can J Public Health. 1986;77(5):359-362.

29. National Cancer Institute. Eating at America's Table: Quick Food Scan. 2000. Available from: http://riskfactor.cancer.gov/diet/screeners/ fruitveg/bymeal.pdf. Accessed July 12, 2011.

30. Floyd DL, Prentice-Dunn S, Rogers RW. A meta-analysis of research on protection motivation theory. J Appl Soc Psychol. 2000;30(2): $407-429$.

31. Milne S, Sheeran P, Orbell S. Prediction and intervention in healthrelated behavior: a meta-analytic review of protection motivation theory. J Appl Soc Psychol. 2000;30(1):106-143.

32. Hay JL, Buckley TR, Ostroff JS. The role of cancer worry in cancer screening: a theoretical and empirical review of the literature. Psychooncology. 2005;14(7):517-534.

33. McCaul KD, Branstetter AD, Schroeder DM, Glasgow RE. What is the relationship between breast cancer risk and mammography screening? A meta-analytic review. Health Psychol. 1996;15(6):423-429.
International Journal of Women's Health

\section{Publish your work in this journal}

The International Journal of Women's Health is an international, peerreviewed open-access journal publishing original research, reports, reviews and commentaries on all aspects of women's healthcare including gynecology, obstetrics, and breast cancer. Subject areas include: Chronic conditions (migraine headaches, arthritis, osteoporosis);

\section{Dovepress}

Endocrine and autoimmune syndromes; Sexual and reproductive health; Psychological and psychosocial conditions. The manuscript management system is completely online and includes a very quick and fair peer-review system. Visit http://www.dovepress.com/ testimonials.php to read real quotes from published authors. 